Meta

Journal des traducteurs

Translators' Journal

\title{
Olgierd Adrian Wojtasiewicz - un grand oublié de la traductologie en Pologne
}

\section{Małgorzata Tryuk}

Volume 60, numéro 2, août 2015

$60^{\mathrm{e}}$ anniversaire. Les horizons de la traduction : retour vers le futur $60^{\text {th }}$ Anniversary. Translation's Horizons: Back to the Future

60mo aniversario. Los horizontes de la traducción: regreso al futuro

URI : https://id.erudit.org/iderudit/1032926ar

DOI : https://doi.org/10.7202/1032926ar

Aller au sommaire du numéro

Éditeur(s)

Les Presses de l’Université de Montréal

ISSN

0026-0452 (imprimé)

1492-1421 (numérique)

Découvrir la revue

Citer ce document

Tryuk, M. (2015). Olgierd Adrian Wojtasiewicz - un grand oublié de la traductologie en Pologne. Meta, 60(2), 375-375.

https://doi.org/10.7202/1032926ar d'utilisation que vous pouvez consulter en ligne.

https://apropos.erudit.org/fr/usagers/politique-dutilisation/ 


\title{
Olgierd Adrian Wojtasiewicz - un grand oublié de la traductologie en Pologne
}

\author{
Malgorzata Tryuk \\ Université de Varsovie, Varsovie, Pologne \\ m.tryuk@uw.edu.pl
}

Olgierd Adrian Wojtasiewicz (1916-1995), linguiste, sinologue, sémiologue et universitaire polonais, publie en 1957, dans la très prestigieuse maison d'édition Ossolineum un ouvrage de petite taille, mais de grande ambition, intitulé Wstęp do teorii tłumaczenia [Introduction à la théorie de la traduction]. Cinquante ans après sa parution, ce petit livre, totalement inconnu en dehors de la Pologne, continue à inspirer, intriguer, influencer les traductologues polonais, car, pour nombre de ses adeptes, il n'a rien perdu d'actualité. Pour d'autres, par contre, les idées qu'il contient n'ont de valeur que de témoignage d'une étape particulière de cette discipline, mais ne peuvent plus être appliquées dans les recherches modernes en traductologie. Mais pour les continuateurs de sa pensée de même que pour ses détracteurs, Olgierd Adrian Wojtasiewicz continue d'être appelé le père fondateur de la traductologie polonaise.

L'auteure de la présente communication propose de présenter brièvement les thèses principales contenues dans cet ouvrage et de rechercher par la suite les causes probables de la totale méconnaissance des idées de Wojtasiewicz en Europe. Était-il victime de sa thèse sur l'intraduisibilité, donc de l'impossibilité de traduire son ouvrage dans les langues de plus grande diffusion? Était-il concurrencé par d'autres théories traductologiques qui ont fait leur apparition à la même époque et qui ont gagné par la suite le monde entier?

Dans la deuxième partie de la communication, l'auteure se propose de confronter la pensée théorique d'Olgierd Adrian Wojtasiewicz avec les tendances actuelles en traductologie, notamment avec les courants postmodernistes et postcoloniaux.

Professeure titulaire en traductologie et interprétologie à l'Institut de linguistique appliquée de l'Université de Varsovie, directrice du programme European Masters in Conference Interpreting et directrice des études doctorales dans l'institut précité. Auteure d'une dizaine de monographies et d'une cinquantaine d'articles sur la traduction et l'interprétation en polonais, français et en anglais. Parmi ses dernières publications figurent notamment: On Ethics and Interpreters. Peter Lang (sous presse) et L'interprétation communautaire. Des normes et des rôles dans l'interprétation. 2004. Warszawa: Wyd. TEPIS. 